\title{
Editorial Introduction African Ways of Knowing, Worldviews and Pedagogy
}

\author{
Samson Nashon \\ samson.nashon@ubc.ca \\ David Anderson \\ david.anderson@ubc.ca \\ Handel Wright \\ handel.wright@ubc.ca \\ University of British Columbia
}

This special issue of Journal of Contemporary Issues in Education comprises of four essays that in one way or the other focus on African thought and education. The essays were part of the presentations during our African Symposium entitled "African Education: Worldviews, Ways of Knowing \& Pedagogy" held at the University of British Columbia in November 2006. The essays present nuances that demonstrate the underlying principles that guide traditional education practice. Each of the essays captures the essence of African philosophies engrained in the knowledge construction, retention and application process. What is evident in the essays is the thematic message of social order rooted in respect and tolerance.

Constantine Ngara's article, African Ways of Knowing and Pedagogy Revisited, advocates a strong case for spirituality-centered thought and wisdom as a definite paradigm of knowing in Africa. Ngara argues that spirituality-centered wisdom not only defines African personhood but it also provides the needed clues and hopes for surmounting the puzzle of the lack of development in Africa by rethinking the pedagogy of Africa's current-day education systems (returning to the source).

This perspective is derived from the view that African ways of knowing have been denigrated, unvalued and not in anyway incorporated into curriculum planning of Africa's modern-day educations systems. Most education planners in Africa tend to be in favor of "more enlightened" western-oriented curriculum and schooling whose pedagogical and philosophical roots are grounded in western thinking. Ngara builds that case that indigenous ways of knowing shape the background cognitive structures that the average African child brings to school, and, hence, he advances the view that learning and making sense of the world is mediated by ones own cultural knowledge, values, and deep-rooted ways of knowing. Moreover, he concludes that if a people's culture and values are not integrated in the communication interchange, then a sense of alienation ensues and no development can be expected. Thus, the way forward for Africa's future is to understand African ways of knowing and to embed these into a re-modernize practice of curriculum and pedagogy.

Ngara illustrates the need for a spirituality-centered thought and wisdom as a definite paradigm of knowing in Africa by considering four case examples of ways of knowing applicable to modern life in Africa - Knowing through taboos, Knowing through collective wisdom and experience, Knowing through faith, and Knowing through

Journal of Contemporary Issues in Education, 2007, 2(2), pp. 1-6.

ISSN 1718-4770 @ 2007 University of Alberta

http://ejournals.library.ualberta.ca/index.php/JCIE 
communication (spiritual wisdom). The cases graphic illustrate the mediation of deeprooted cultural knowledge that directs both the thinking and behavior of modern-day African citizens. These case illustrations are, of course, an exemplar set of a rich diversity of indigenous ways of knowing. There are many ways of knowing and many ways in which each of these exemplars might be considered. The existence of a rich diversity of African ways of knowing only reinforces Ngara's call for more situated research to be undertaken that more deeply elucidates its forms and character. More importantly, if the forward for Africa's is "returning to the source", then research which focuses on ways to harness indigenous ways of knowing to the service of a re-modernize practice of curriculum and pedagogy ought to be a priority.

Ngara, elegantly concludes that, development in Africa will be enhanced by pedagogy of liberation that among other things restores African dignity and self-efficacy. African ways of knowing constitute invaluable aspects of African heritage that harmonize Africa's past broken story of development with its modern realities of globalization.

Jenipher Owuor's article on, Integrating African Indigenous Knowledge in Kenya's Formal Education System: The potential for sustainable development, explores the definition of indigenous knowledge, rationale for valuing indigenous knowledge in formal education, and the dilemmas that undermine efforts to integrate such knowledge in the school curriculum in the Kenyan context. Owuor makes the point that recognizing the virtues of integrating indigenous knowledge and practices in the Kenyan education system is not a new concept, rather this has been a stated goal of education reforms since independence in 1963. Implicit within this goal has been to reconstruct the curriculum at all levels of the education system to reflect the diverse indigenous ways of knowing, promote social change, and the empowerment of Kenyans. Moreover, reclaiming cultural identities rooted within the authentication of indigenous traditions has been perceived as a way forward to decolonizing western dominated school curricula, hence making education more relevant and practical in addressing the needs of Kenya's citizens. Notwithstanding, the realization of these goals is still far from the reality of current day curriculum and pedagogical reforms in Kenya.

Owuor outlines several points on the nature and character of indigenous ways of knowing that are highly pertinent to curriculum and pedagogical reforms. For example, indigenous education practices among Kenyan ethnic communities are holistic in nature, integrating all activities including rituals and skills required to sustain cultural practices, life of the family, and community. These traditional education practices aim to prepare individuals for communal responsibility and interpersonal relationships as critical aspects of the learning process. In addition, it involves the expertise of multiple teachers given the multiple natures of roles and responsibilities in life through which the youths need to be mentored and guided. Hence, the communal responsibility of education forms the basis for indigenous pedagogy.

Despite these common characteristics, Owuor cautions that educators and curriculum developers need to be cautious and avoid bundling together the diverse Kenyan ways of knowing under one category of indigenous knowledge, since this is likely to jeopardize the potentially unique and important contribution that specific forms of indigenous knowledge can make to development within specific localities and among local groups who embrace such knowledge. In addition, Owuor identifies an important 
tension between the western-based schooling curriculum and pedagogy, that recognizes teachers' professionalism as central in facilitating student learning, and indigenous view which holds the role of members of local communities, such as elders, as a key component of pedagogy. This and other tensions discussed in the article make a sobering discussion of the challenges that confront integration of the indigenous knowledge in the school environment that already privileges western epistemologies against indigenous epistemologies, a condition that continues to create hegemony in Kenya's school knowledge construction.

Owuor argues that to avert the current economic marginalization, education stakeholders through the process of education should inculcate into our children the virtue of taking lead in their own learning based on their local experiences. It is only through playing leading roles in shaping their own destiny in development of their communities that Kenyan students can be able to appreciate working with outsiders in a reciprocal way with the understanding that both parties have knowledge that can be shared and valued.

In her article, Loosing my western baggage: an autobiographical case for relocating human rights within cultural studies discourses, Pearl Hunt uses her experience of preparing, traveling to and participating in a transnational collective of peace educators to attend a global peace conference "Mpambo - One People Multiple Dreams of a Different World" in Uganda to question the way cultural discourses in academia are organized and offered. She interrogates the nature of these discourses that appear on the surface to be inclusive and yet in framing and the manner in which content is unveiled reveals the subtle dominance of western culture. Hunt further uses her experience outside the conference venue to participate in authentic outreach activities to reflect on the western misunderstanding of the 'African'.

What is striking in her paper is the reference to the social change of the 70 s and 80 s in developing her use of "identity" as a powerful methodology to understanding the nature of African 'unity'. According to Hunt, Wright's (2003) framing of activist cultural studies has shaped cultural studies discourses by seeking to "relocate aesthetics within a socio-political context". Her intent in promoting the connection between cultural work and social justice frames her inquiry into African cultural studies. Hunt sees cultural studies as a product of relocating social justice within academic discourse. But she reckons that the academic discourse is often framed by western epistemologies.

Critiquing the populist theatre explosion of the 1970s in both Canada and the US, which resisted institutionalization of the repertory theatres in favour of collective and collaborative open-air creations, Hunt still sees the perpetuation of the Brechtian model of populist theatre being heavily influenced by Eurocentricism.

Citing "The Kamirithu People's Theatre", which she characterizes as demonstrating the centrality social justice in African cultural studies, Hunt illustrate how theatre can play a central role in agitating for political as well as social change. She considers this to be a representation of the real fieldwork and criticizes trends in contemporary research methodologies that distance researchers from the field and fieldwork. 
In summary, Hunt advocates cultural studies that embrace the African construction of identity as being collective. This view of identity, which she calls "collective identity", is characteristic of African ways of knowing. She decries the prevailing situation that subordinates people's knowledge, histories, and experiences. In an indirect way she calls for a reexamination of the western liberal epistemology, which embodies individualism with a view to tapping from the African notion of collective identities for the purposes of peace and social justice.

Hunt uses her strong knowledge of music as an agent of social change, which also has the ability to transcend cultural borders in articulating her position on the way African cultural studies discourses ought to evolve. This is evident in her expression that "...music has the capacity to create solidarity against state sanctioned brutality and repeated human rights abuses". In offering this, she does not spare the African ethnicities and other malpractices into which people take refuge with a view to perpetuating ethnic hatred and power dominance by citing the Rwandan Genocide as one case that the world will always regret.

Hunt cites several "objects" around which the notion of "collective identities" has manifested over millennia, such as the source of the river Nile. She eloquently uses her travel luggage that never arrived at the Entebbe Airport, Uganda until on the day she was departing from Uganda and questions of what use were some of the items she had packed. Hunt uses her own realization that she did not need all that had she packed after all to ague for a need for the West to view Africa as part of the collective by sharing what they do not need. Thus she says, "As educator and cultural workers we have the responsibility to question the exclusion of epistemologies that rest outside the dominant western narrative". This by extension calls on appreciation and understanding of non western ways of knowing.

Dalene Swanson's article, Ubuntu: An African contribution to (re)search for/with a 'humble togetherness', is a philosophical and socio-political contribution to understanding the relevance of African epistemology and worldviews to methodological, personal and ethical engagement in qualitative research. Her contribution is a discussion in two parts.

The first part addresses the Southern African indigenous philosophy of Ubuntu, providing it with a working definition and situating it within African epistemology and the socio-political contexts of its invocation. She situates her arguments by introducing a theoretical approach rooted in an interrogation of the relationship between constructs of identity, ideology, knowledge and context. Introducing ideas within poststructuralist and postcolonial discourses, she discusses some of the ways in which indigenous perspectives have been rendered absent, attended to, or challenged, noting the (de)emphases given to some of the various discourses on indigeneity and 'otherness.' She points to the continued politics of postcolonial identities in the African context, which centre on Africa, its diaspora and epistemologies, as being articulated and accorded a contested presence. To enter into this debate, she uses the African epistemology of "Ubuntu" as a way of engaging in the ongoing dialogues in Africa and elsewhere. The article then raises critical concerns about Ubuntu's embrace in the Truth and Reconciliation Commission and its promulgation as an ideology within the nation-building project of post-apartheid 
South Africa. Such concerns are referenced with respect to Ubuntu's formulation within the advocacies of cultural nationalism. In particular, Swanson observes that the leadership in South Africa has often appropriated Ubuntu to create a conformist national citizenry in the name of nation-building and to deflect criticism of the government. This approach, she believes, smacks of similar authoritarian traits to that of the earlier apartheid regime. Nevertheless, the discussion commits to perspectives of possibility towards disrupting neoliberalism and decolonizing hegemonic meanings, and advances a debate towards transformation and transcendence within a post-apartheid context.

Using Desmond Tutu as a custodian and advocate of Ubuntu, Swanson conveys that Ubuntu is rooted in wisdom and lived experience, respect and honour. While referred to as "Ubuntu" in Sub-Saharan Africa, this form of African humanism is found in many languages throughout the continent. Swanson characterizes Ubuntu as a philosophy of becoming human, where one gains one's human dignity in the manner in which one respects 'the other' and in how one views one's place in the larger collective of humanity. As an African philosophy of love, Ubuntu conveys the spirit of respectfulness and togetherness and, in this sense, remains a viable advocacy for forging ahead with the nation-building project.

The second part follows on from the arguments in the first, which set the stage for a narrative journeying of a more personal nature. This part of the article offers a reflexive account of how Ubuntu was used as a guiding principle for engagement in fieldwork and the structuring of a qualitative research methodology. The narrative tone is different to that of the first part, which offered critical perspectives within a broad socio-political discussion. The second part moves from a national level to a local level. It locates more personal interactions and a search for a "humble togetherness' within the context of a township school in South Africa. By using the Truth and Reconciliation Commission's deliberations and her own research in schooling contexts of socioeconomic poverty in post-apartheid South Africa, she sees Ubuntu epistemology as a contribution to be made to social science research in general. This necessarily involves establishing empathetic rapport with the research community and engaging with sensitivity and insight into issues of power, subjectivity, context, ideology, ethics, and lived experience. In this sense, Ubuntu becomes a guiding principle for research engagement. Swanson makes a case for how, through the spirit of Ubuntu and reflexive narratizing, Ubuntu might guide the process of deconstructing hegemonic meanings and point to the existence of other possibilities of being and knowing in the world.

The article closes with a somewhat cautionary note on how a philosophy such as Ubuntu might be taken up in a political institutional forum that has unwanted implications, but it also advocates for Ubuntu in providing legitimizing spaces for transcendence of injustice and a more democratic, egalitarian and ethical engagement of human beings in relationship with each other. In this sense, Ubuntu offers hope and possibility in its contribution to human rights. 
In conclusion, the four articles tease out what is not apparent on the surface but whose power is unexploited; be it in Ngara's African ways of knowing, Owuor's traditional knowledge, Hunt's social justice in African culture and Swanson's humanness conveyed in the Ubuntu philosophy, there is a uniting revelation that the African worldviews, ways of knowing and pedagogy, there is unity in diversity as an underlying principle in African thought.

Samson Nashon, David Anderson \& Handel Wright

University of British Columbia

Guest Editors 